\title{
Troglitazone selectively inhibits glyoxalase I gene expression
}

\author{
L.Wu ${ }^{1}$, E. Eftekharpour ${ }^{1}$, G. F. Davies ${ }^{2}$, W.J. Roesler ${ }^{2}$, B.H.J.Juurlink ${ }^{1}$ \\ ${ }^{1}$ Department of Anatomy and Cell Biology, College of Medicine, University of Saskatchewan, Saskatoon, SK, Canada \\ ${ }^{2}$ Department of Biochemistry, College of Medicine, University of Saskatchewan, Saskatoon, SK, Canada
}

\section{Abstract}

Aims/hypothesis. The hyperglycaemia associated with diabetes causes excessive production of cytotoxic methylglyoxal, an $\alpha$-oxo-aldehyde. The glyoxalase system, composed of glyoxalase I and glyoxalase II, with glutathione (GSH) as the cofactor, plays an important role in the detoxification of $\alpha$-oxo-aldehydes. We tested the hypothesis that troglitazone, an insulin-sensitizing drug previously used in the treatment of Type II (non-insulin-dependent) diabetes mellitus, up-regulates the glyoxalase system either by increasing phase 2 enzyme activities and thereby increasing cellular GSH, or, by inducing glyoxalase enzyme activities.

Methods. Human astroglial cells, rat hepatocytes and cardiac myocytes were cultured and exposed to either troglitazone, or tertiary-butylhydroquinone (tBHQ, a phase 2 enzyme inducer). Glutathione content, advanced glycation end products (AGEs) and enzyme (glyoxalase I, glyoxalase II as well as the phase 2 enzymes, glutathione S-transferase and thioredoxin reductase) activities were determined. Glyoxalase I mRNA was also measured.
Results. Troglitazone had no effect on cellular GSH nor phase 2 enzyme activities but significantly reduced the activities of glyoxalase I and II; this inhibitory effect was concentration-dependent and timedependent and was associated with reduced mRNA contents and increased AGEs formation. Rosiglitazone had no effect on glyoxalase I gene expression. tBHQ, a classic phase 2 enzyme inducer, had no effect on the glyoxalase system but did increase glutathione contents and the activities of glutathione S-transferase and thioredoxin reductase.

Conclusion/interpretation. Our study shows that troglitazone is a selective inhibitor of the glyoxalase system. This inhibition of the glyoxalase system could contribute to troglitazone's hepatotoxic action which has previously been reported in a small percentage of individuals. [Diabetologia (2001) 44: 2004-2012]

Keywords Advanced glycation end products, diabetes mellitus, gene expression regulation, hepatotoxicity, hypoglycaemic agents, insulin resistance, oxidative stress.
Received: 26 February 2001 and in revised form: 12 July 2001

Corresponding author: Bernhard H.J. Juurlink, Department of Anatomy and Cell Biology, University of Saskatchewan, 107 Wiggins Road, Saskatoon, SK, Cnada S7N 5E5,

e-mail: juurlink@duke.usask.ca

Abbreviations: AGEs, Advanced glycation endproducts; DCFH, 5-(and-6)-carboxy-2'7'-dichlorodihydrofluorescein; DMSO, dimethylsulfoxide; DTNB, 5,5'-dithiobis-2-nitrobenzoic acid; Gly-I, glyoxalase I; Gly-II, glyoxalase II; GSH, glutathione; tBHQ, tertiary-butylhydroquinone; RPPO, ribosomal phosphoprotein 0
The formation of the strong oxidant methylglyoxal, an $\alpha$-oxo-aldehyde, is increased in hyperglycaemia which is associated with both Type I (insulin-dependent) and Type II (non-insulin-dependent) diabetes mellitus in humans [1]. The glyoxalase system, consisting of two enzymes (glyoxalase I and glyoxalase II) and one cofactor, glutathione (GSH) [2], plays an important role in scavenging methylglyoxal. Glyoxalase I catalyses the formation of S-D-lactoylglutathione from the hemithioacetal that is formed nonenzymatically from methylglyoxal and GSH. Glyoxalase II hydrolyses S-D-lactoylglutathione to D-lac- 
tate, regenerating GSH. The accumulation of $\alpha$-oxoaldehydes including methylglyoxal due to an impaired detoxification function of glyoxalase system could result in protein glycation, DNA damage [1], vascular dysfunction and atherosclerosis [3]. These observations indicate that the glyoxalase system plays an important role in the causation and maintenance of diabetic vascular complications. Indeed, reduced activity in the glyoxalase system has been reported in streptozotocin-diabetic MF1 mice [4] and rats [5]. An up-regulation of glyoxalase activities in diabetes would be expected to reduce methylglyoxal concentrations and to slow down or reverse the protein glycation process. Indeed, cell glyoxalase I transfectant lines have an increased ability to scavenge methylglyoxal and tolerate higher levels of methylglyoxal (6). Furthermore, metformin, an antihyperglycaemic drug, reduces methylglyoxal concentrations in Type II diabetic patients [7].

Troglitazone, a member of the thiazolidinedione family, is an antidiabetic agent that has been used clinically in the management of Type II diabetes because it can improve sensitivity of muscle and adipose tissues to insulin and can inhibit hepatic gluconeogenesis [8-10]. Troglitazone also has an antihypertensive effect [11] and inhibits vascular smooth muscle cell growth [12]. Some of the antihyperglycaemic actions appear to be through down-regulation of the expression of the gluconeogenic enzymes phosphoenolpyruvate carboxykinase and glucose-6-phosphatase [13] and up-regulation of c-Cbl-associated protein [14]. At the molecular level, a major mode of action of troglitazone is binding and activating the Peroxisome Proliferator Activated Receptor- $\gamma$ (PPAR- $\gamma$ ) that regulates the transcription of a number of genes, including insulin responsive genes, critical for the control of glucose and lipid metabolism [15].

Troglitazone has been reported to have antioxidant activity. It has a moiety structurally similar to vitamin $\mathrm{E}$ and has been reported to protect low-density lipoprotein (LDL) from oxidative modification [16]. We questioned whether troglitazone could decrease oxidative stress by other mechanisms. Overexpression of glyoxalase I in bovine endothelial cells has been shown to prevent the hyperglycaemia-induced protein glycation [17]. There has been no study on the possible effect of troglitazone on the glyoxalase system. We hypothesized that possibly troglitazone: 1) up-regulates the glyoxalase system, or, 2) acts as a phase 2 enzyme inducer [18] and thereby increases GSH by up-regulating $\gamma$-glutamyl-cysteinyl synthase, the rate-limiting enzyme in GSH synthesis [19] which is under the control of the anti-oxidant response element [20]. An increase in the GSH would not only facilitate the detoxification of $\alpha$-oxo-aldehydes by glyoxalase system but also reduce the oxidative stress by a variety of other mechanisms [21]. As a positive control for up-regulation of phase 2 enzymes, we also examined the effect of the phase 2 enzyme inducer, tertiary-butylhydroquinone (tBHQ).

\section{Materials and methods}

Cell preparation. Three cell preparations were used in this study. One was H11 human astroglioma cells clonally derived from a proliferating glial population in cultures established from adult human temporal lobe resected because of intractable epilepsy [22]. H11 cells were plated in $60-\mathrm{mm}$ dishes in DMEM containing $10 \%$ FCS and incubated at $37^{\circ} \mathrm{C}$ in a humidified atmosphere comprised of $5 \% \mathrm{CO}_{2}$ in air. Cells were used for experimentation when cultures attained confluency. The second cell type examined was the $\mathrm{H} 9 \mathrm{c} 2$ rat cardiac myocyte [23] obtained from the American Type Tissue Collection. These cells were grown in DMEM containing $10 \%$ FCS.

Rat hepatocytes in primary culture were also used. Hepatocytes were isolated from Sprague-Dawley rats using the collagenase perfusion method [24] and cells placed on collagen coated $100 \mathrm{~mm}$ dishes at a concentration of 2 million cells per dish. After a 4-h incubation in the presence of DMEM containing $10 \% \mathrm{FBS}$, the medium was replaced with serum-free DMEM containing $0.2 \%$ bovine serum albumin and incubated for another additional $8 \mathrm{~h}$ and then treated for $8 \mathrm{~h}$ with troglitazone, rosiglitazone or dimethylsulfoxide (DMSO) vehicle. Animals were treated in accordance with the guidelines of the Canadian Council on Animal Care.

Measurement of enzyme activities. The activities of glyoxalase I and glyoxalase II were determined following McLellan and Thornalley's method [25]. In brief, the activity of glyoxalase I was evaluated by monitoring the increase in absorbance at $240 \mathrm{~nm}$ due to the formation of S-D-lactoylgutathione and that of glyoxalase II by monitoring the decrease at $240 \mathrm{~nm}$ due to the hydrolysis of S-D-lactoylgutathione in the presence of homogenates. The activity of glutathione S-transferase was measured by monitoring the change in the absorbance at 340 $\mathrm{nm}$ due to the thioether formation in the presence of homogenates [26]. The activity of thioredoxin reductase in the homogenates was measured by monitoring the changes in the absorbance at $412 \mathrm{~nm}$ due to the reduction of 5,5'-dithiobis-2-nitrobenzoic acid (DTNB) in the presence of NADPH [27] as we have previously done [28]. Protein concentrations were determined by bicinchoninic acid procedure [29] using bovine serum albumin as the reference.

Measurement of GSH contents. The monochlorobimane procedure was used to measure GSH contents as described previously [30]. The GSH-monochlorobimane adduct was measured using a Labsystems Fluoroskan II (MTX Lab Systems, Vienna, Va., USA) microtitre fluorometric reader with excitation at $380 \mathrm{~nm}$ and emission measured at $470 \mathrm{~nm}$.

Measurement of oxidative stress. Oxidative stress was determined as described in our previous publication [31]. Briefly, cells were preloaded with a membrane permeable agent 5-(and-6)-carboxy-2'7'-dichlorodihydrofluorescein ester (DCFH ester) for $30 \mathrm{~min}$ before different treatments. The DCFH ester becomes the membrane impermeable DCFH in the presence of cytosolic esterases. DCFH is oxidized to the fluorescent DCF principally by strong oxidants. Oxidative stress was determined by monitoring the DCF content with the microtitre fluorometer with excitation at $495 \mathrm{~nm}$ and emission at $525 \mathrm{~nm}$. 
Measurement of advanced glycation end products. Methylglyoxal as well as other $\alpha$-oxo-aldehydes interact with proteins to form advanced glycation end products (AGEs) that fluoresce at $440 \mathrm{~nm}$ when excited at $370 \mathrm{~nm}[32,33]$; hence, AGEs were measured fluorometrically in medium serum and in cell protein of H11 astroglioma cell cultures.

Northern blot. A 622 bp glyoxalase probe [34] was isolated from a $2.69 \mathrm{~Kb}$ pUC vector (a generous gift from Dr. K. Tew) using EcoRI. Total RNA was isolated using TriZol Reagent (Gibco/BRL, Burlington, Ontario, Canada). For determining equivalency of RNA loading the ribosomal phosphoprotein PO (RPPO) cDNA was used [35]. cDNA probes were random-labelled with $\left[\alpha-{ }^{32} \mathrm{P}\right] \mathrm{dCTP}$ according to the instructions supplied with the hexanucleotide kit (Boehringer Mannheim, Laval, Quebec, Canada).

Northern blot analysis was done by electrophoresing RNA $(20 \mu \mathrm{g})$ through a $1 \%$ agarose-formaldehyde gel, followed by transfer of RNA to GeneScreen Plus membranes (DuPontNew England Nuclear, Boston, Mass., USA), capillary elution and UV-crosslinking to the membrane at $254 \mathrm{~nm}(1200 \mathrm{~mW} /$ $\mathrm{cm}^{2}$, Stratalinker 1800, Stratagene, La Jolla, Calif., USA). The RNA was hybridized to the cDNA probes $\left(10 \cdot 10^{6} \mathrm{cpm}\right)$ in $5 \mathrm{x}$ SSPE $\quad\left(0.75 \mathrm{~mol} / \mathrm{l} \quad \mathrm{NaCl}, \quad 50 \mathrm{mmol} / \mathrm{l} \quad \mathrm{NaH}_{2} \mathrm{PO}_{4}, \quad 5 \mathrm{mmol} / 1\right.$ EDTA, pH 7.4), $0.5 \%$ sodium dodecylsulfate, $5 \cdot$ Denhardt's solution, $10 \%$ dextran sulfate containing $100 \mu \mathrm{g} / \mathrm{ml}$ denatured salmon sperm for $16-20 \mathrm{~h}$ in a rotary hybridization oven (TurboSpeed, Bio/Can Scientific, Mississauga, Ontario, Canada) at $65^{\circ} \mathrm{C}$. Following hybridization, membranes were washed with 2 - SSPE, $0.1 \%$ SDS at room temperature followed by $1 \times \mathrm{SSPE}, 0.1 \%$ SDS at $65^{\circ} \mathrm{C}$. The membranes were exposed to $\mathrm{x}$-ray film at $-80^{\circ} \mathrm{C}$, developed and autoradiograms were scanned and quantified using NIH Image software.

Chemicals and data analysis. Troglitazone was a gift from Parke-Davis (Ann Arbor, Mich., USA) while rosiglitazone was a gift from Smith-Kline Beecham (West Sussex, UK). GSH, tBHQ, xanthine, xanthine oxidase, S-D-lactoylgutathione, 1-chloro-2,4-nitrobenzene, DMSO and glutathione Stransferase were purchased from Sigma Chemical Co (St. Louis, Mo., USA). Monochlorobimane and DCFH ester were purchased from Molecular Probes (Eugene, Ore., USA). Troglitazone and tBHQ were prepared in DMSO and the final concentration of DMSO in the medium was $0.1 \%$. There were no differences in the activities of glyoxalases, the contents of GSH or oxidative stress in the absence or presence of DMSO $(0.1 \%)$ in the cells. Data are expressed as means \pm SEM and analysed using Student's $t$ test or analysis of variance in conjunction with the Newman-Keuls test where applicable. Differences between groups were considered statistically significant when $p<0.05$.

\section{Results}

The effect of troglitazone on the activities of glyoxalases. H11 cells were cultured for $24^{\circ} \mathrm{h}$ with troglitazone or tBHQ. Troglitazone significantly inhibited the activity of glyoxalase $\mathrm{I}$ in a concentration-dependent manner with maximal inhibition seen at $50 \mu \mathrm{mol} / \mathrm{l}$ (Fig.1A). After H11 cells were treated with $50^{\circ} \mu$ moles/l troglitazone, for instance, the activity of glyoxalase I was decreased by $56 \pm 8 \%$ compared to the control group $(p<0.05, n=6)$; however, there was no change in the activity of glyoxalase I after the
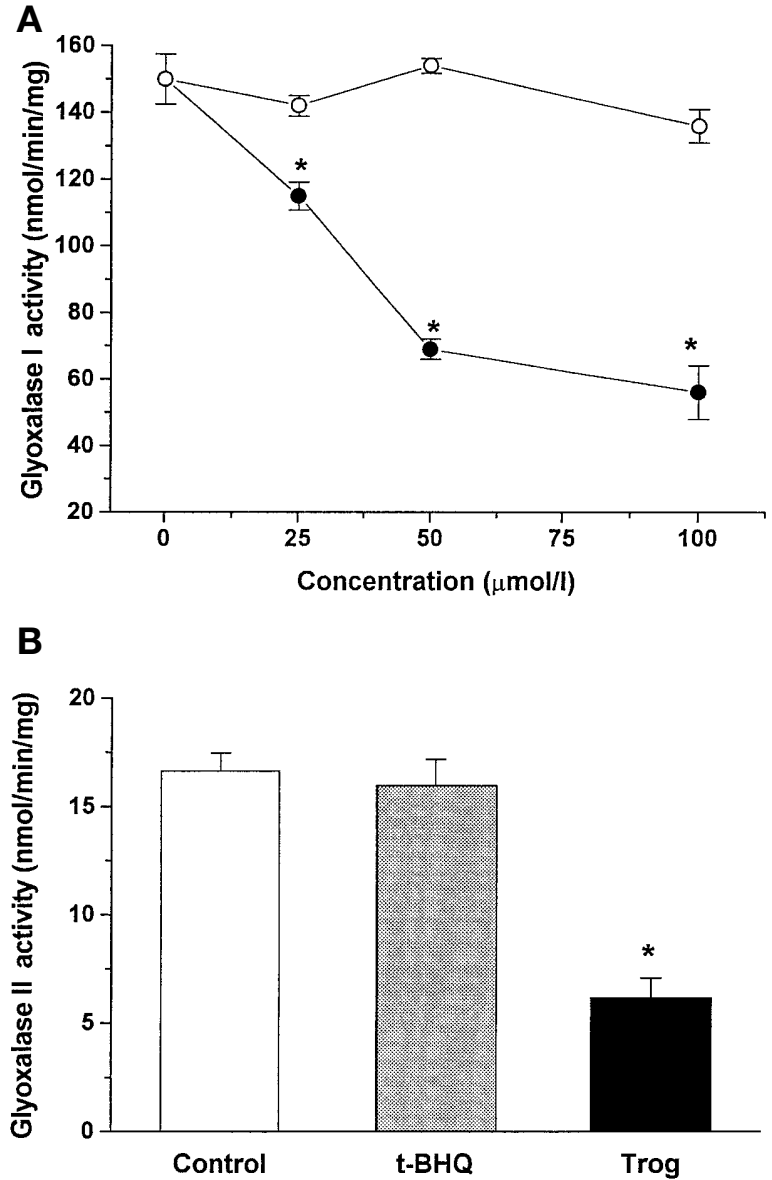

Fig. 1. Effect of a 24-h exposure of troglitazone or $t B H Q$ on the activities of glyoxalases in $\mathrm{H} 11$ cells. A The concentrationdependent effects of troglitazone $(O)$ and $\mathrm{tBHQ}(\bigcirc)$ on the activity of glyoxalase I. B The effects of troglitazone $(100 \mu \mathrm{mol} / \mathrm{l})$ and tBHQ $(100 \mu \mathrm{mol} / \mathrm{l})$ on the activity of glyoxalase II. $n=6$ in A and $n=4$ in B per data point . * indicates $p<0.05$, compared to control group

cells were treated with tBHQ (Fig.1A). Fig. 1B shows that the activity of glyoxalase II in H11 cells was significantly reduced by $63 \pm 5 \%$ after the treatment with $100 \mu$ moles/l troglitazone, but not with tBHQ (100 $\mu$ moles/l).

To determine whether troglitazone inhibited glyoxalase I activity in another cell type, rat hepatocytes grown in primary culture were exposed to troglitazone and glyoxalase I activity measured after $8 \mathrm{~h}$ revealing a dose-dependent troglitazone-induced decrease in glyoxalase I activity (Fig. 2).

The effect of troglitazone on the cellular GSH contents and the activities of phase 2 enzymes. To investigate whether the troglitazone-induced inhibition of glyoxalases was coupled to the regulation of cellular GSH contents, H11 cells were incubated with troglitazone for $24 \mathrm{~h}$ and then the cellular GSH contents were measured. Figure 3 shows that troglitazone at different concentrations ( 25 to $100 \mu \mathrm{mol} / \mathrm{l}$ ) did not signifi- 


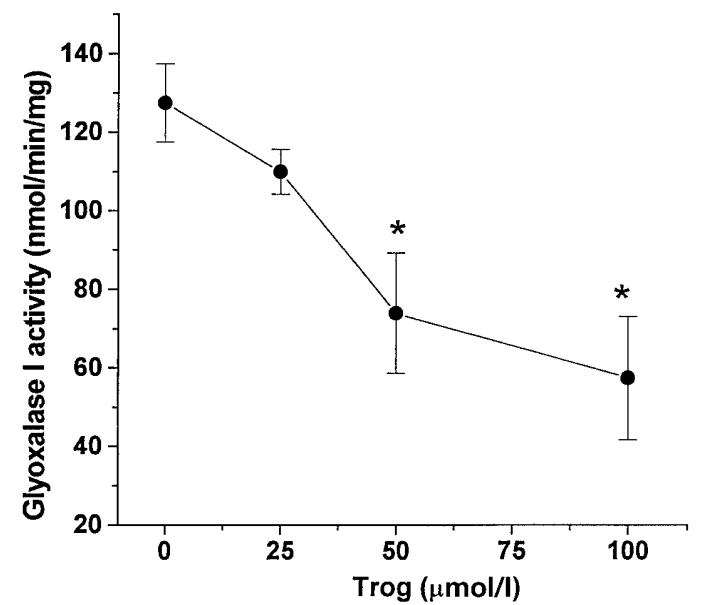

Fig. 2. The effect of an $8 \mathrm{~h}$ exposure of troglitazone on glyoxalase I activity in primary cultures of rat hepatocytes prepared from three different rats. Note that $n=4$ for each data point except for $25 \mu \mathrm{mol} / \mathrm{l}$ troglitazone where $n=3$. *indicates $p<0.05$, compared to the control group

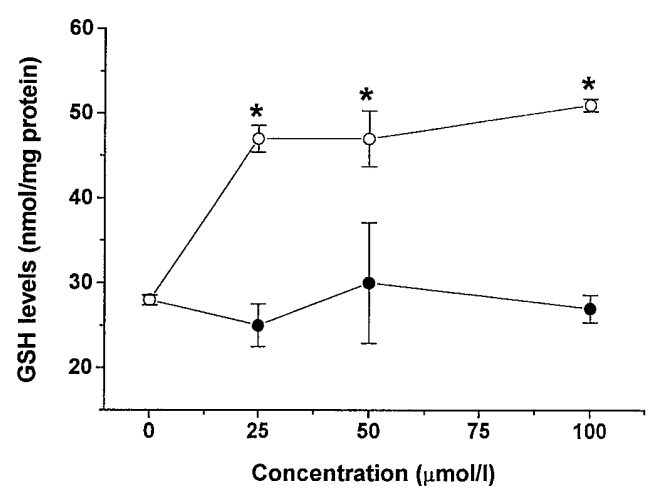

Fig.3. The effects of troglitazone and tBHQ on the cellular GSH contents in H11 cells. GSH contents were measured in the absence or presence of troglitazone $(O)$ or tBHQ $(\bigcirc)$ at different concentrations for 24 h. $n=4$ per data point. * indicates $p<0.05$, compared to control group

cantly change the GSH contents. In contrast, $24 \mathrm{~h}$ incubation with $\mathrm{tBHQ}$ induced a significant increase in $G S H$ contents in these cells.

Whether troglitazone or tBHQ could modify the activity of the phase 2 enzymes in $\mathrm{H} 11$ cells was examined. Troglitazone ( 25 to $100 \mu \mathrm{mol} / \mathrm{l})$ did not induce a significant change in the activity of glutathione S-transferase, although tBHQ increased the activities of this phase 2 enzyme in these cells (Fig. 4A). In addition to GSH, thioredoxin as an electron donor can also protect protein sulfhydryls from oxidation [36]. The oxidized-thioredoxin is reduced by thioredoxin reductase [27]. Figure 4B shows no significant changes in the activity of thioredoxin reductase after incubating the cells with troglitazone for $24 \mathrm{~h}$. However, tBHQ, significantly increased the activity of thioredoxin reductase in these cells.
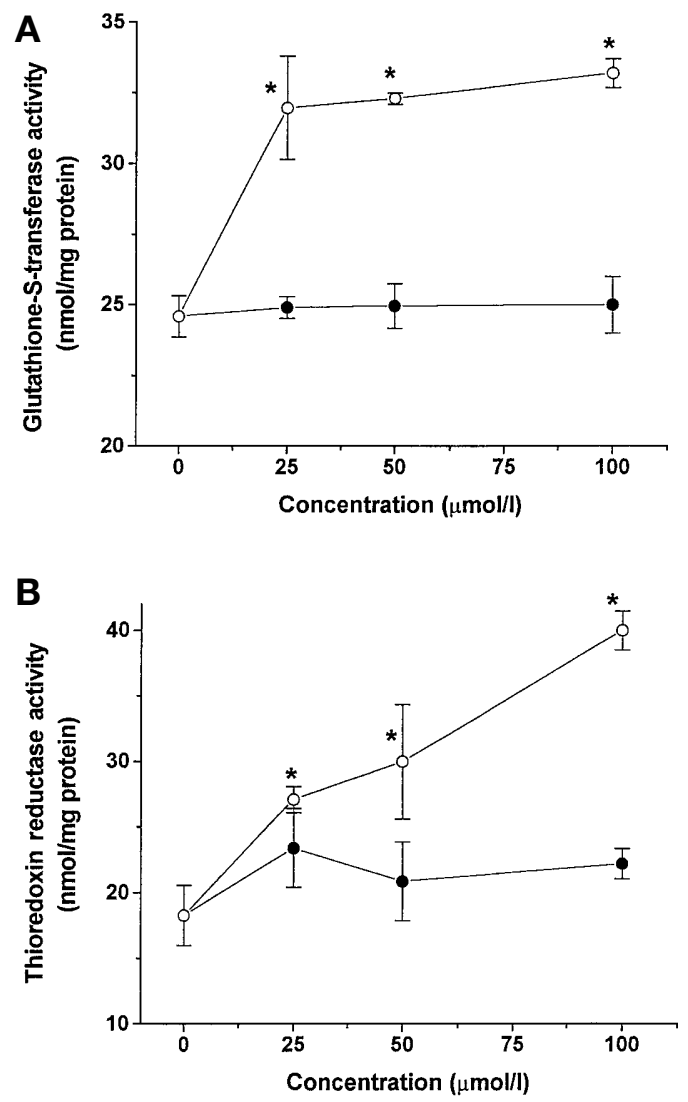

Fig. 4. The effects of troglitazone and tBHQ on the activities of phase 2 enzymes in $\mathrm{H} 11$ cells. After the cells were treated with troglitazone $(\mathbf{O})$ or $\mathrm{tBHQ}(\bigcirc)$ for $24 \mathrm{~h}$, the activities of glutathione S-transferase (A) or thioredoxin reductase (B) were evaluated. Troglitazone had no effect on the activities of both phase 2 enzymes, but tBHQ significantly increased their activities. $n=5$ in $\mathbf{A}$ and $n=4$ in $\mathbf{B}$ for each data point. * Indicates $p<0.05$, compared to control group

The effect of troglitazone on formation of advanced glycation endproducts. To determine whether a reduction in glyoxalase activities is associated with increased methylglyoxal-associated cell damage, the formation of AGEs in H11 astroglioma cells was examined. There was a significant increase in AGE formation following a $24 \mathrm{~h}$ exposure to troglitazone, both in medium and in cells (Fig. 5 ).

The effects of troglitazone on oxidative stress. A significant increase in the oxidative stress, as measured by oxidation of DCFH and as compared with the control group, was observed after the H11 cells were treated for $24 \mathrm{~h}$ with troglitazone at the concentrations of 50 or $100 \mu \mathrm{mol} / \mathrm{l}$. In contrast, the treatment of the cells with tBHQ for $24 \mathrm{~h}$ resulted in a reduction in the oxidative stress (Fig.6). A linear regression analysis of $G S H$ contents against the oxidative stress levels showed that changes of oxidative stress bore no relation to cellular GSH content in the presence of troglitazone $(r=-0.05, p>0.05)$. However, a negative correlation between the GSH contents and oxi- 


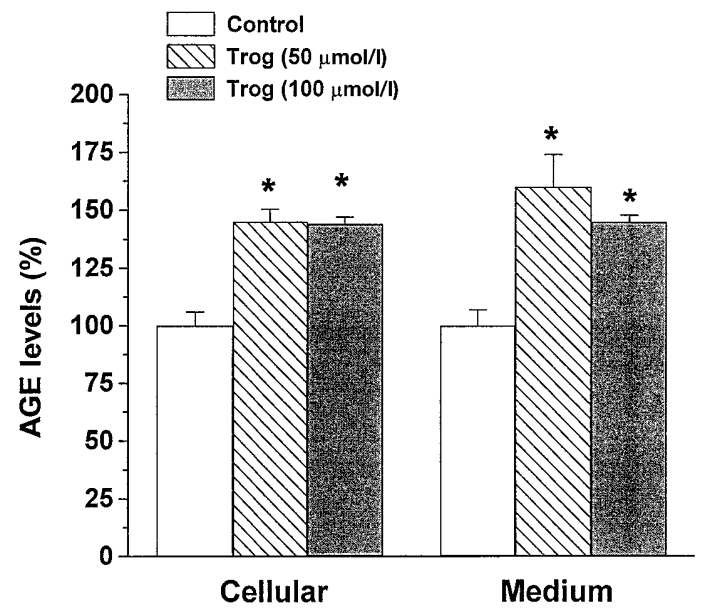

Fig. 5. The effect of a $24 \mathrm{~h}$ exposure to 50 and $100 \mu \mathrm{mol} / \mathrm{l}$ troglitazone on advanced glycation end products in $\mathrm{H} 11$ astroglioma cells as measured fluorometrically. $n=3$ per data point, * indicates $p<0.05$

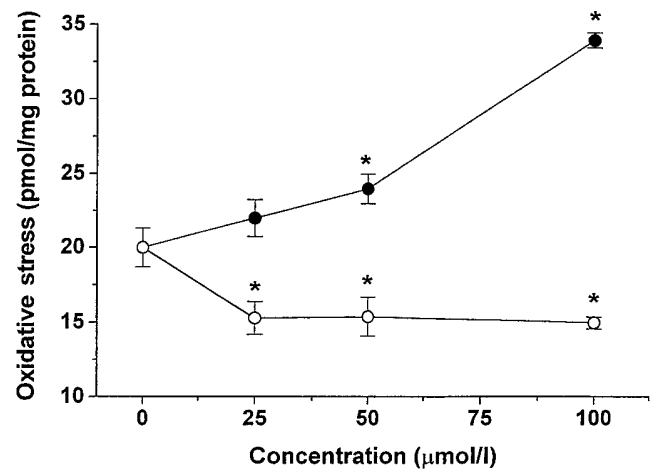

Fig.6. The effects of troglitazone $(\bigcirc)$ and $\mathrm{tBHQ}(\bigcirc)$ on the cellular oxidative stress in H11 astroglioma cells. DCFH oxidation was measured in the absence or presence of troglitazone or tBHQ at different concentrations for $24 \mathrm{~h}$. $n=4$ per data point. * indicates $p<0.05$, compared to control group

dative stress was found in the cells treated with tBHQ $(r=-0.99, p<0.05)$.

The troglitazone-induced increase in oxidative stress was time-dependent in H11 cells. A significant increase in oxidative stress was observed after the cells were treated with troglitazone $(100 \mu$ moles/l) as early as $30 \mathrm{~min}$ after the exposure to troglitazone. Within $2 \mathrm{~h}$, this increase in oxidative stress gradually subsided. However, the troglitazone treatment beyond $2 \mathrm{~h}$ produced the second tide of oxidative stress which increased linearly up to $24 \mathrm{~h}$ (Fig. 7A). A similar pattern of time-dependent changes was also found in the activity of glyoxalase I in the presence of troglitazone. The inhibitory effect of troglitazone on the activity of glyoxalase I was not significant until the incubation time was $4 \mathrm{~h}$ or longer (Fig.7A). On the other hand, there was no significant change in the cellular GSH level after the treatment of cells
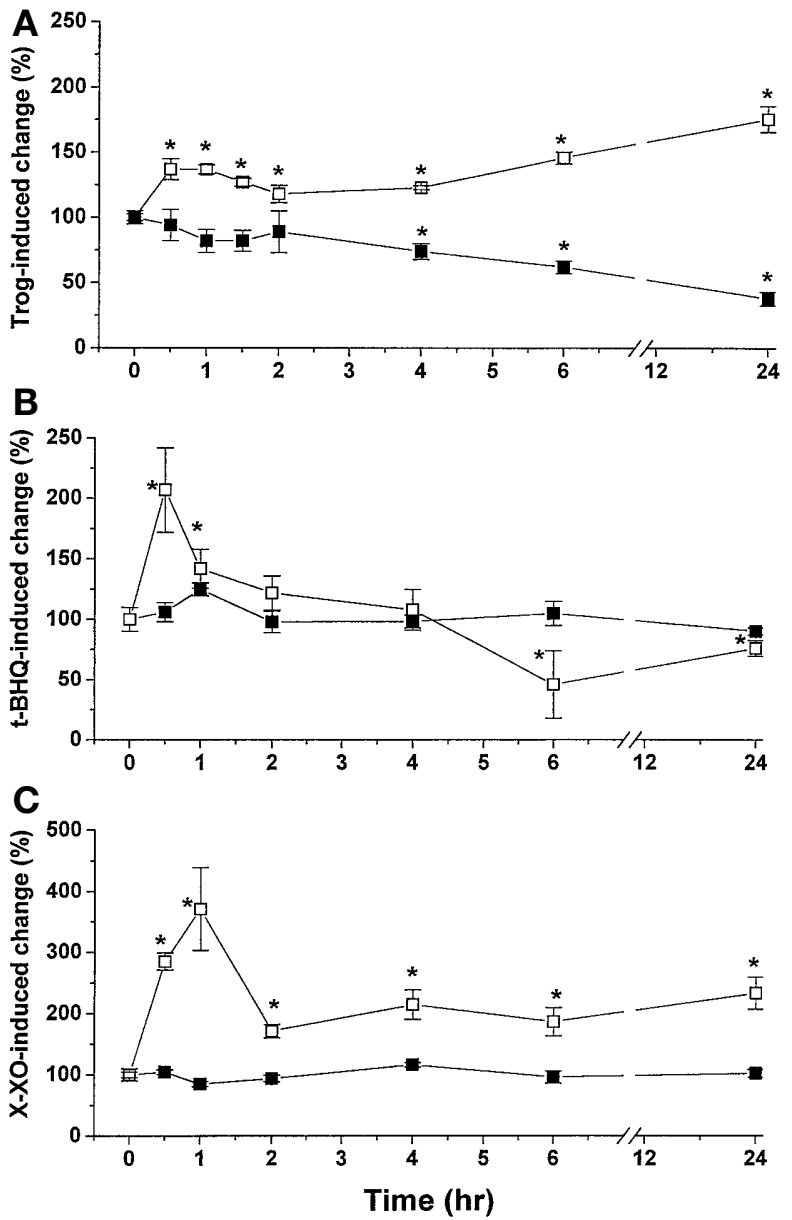

Fig. 7. The time-dependent changes in the glyoxalase I activity (ם) and oxidative stress levels ( $\square$ ) in H11 astroglioma cells. The oxidative stress and glyoxalase I activity were determined after the treatment of cells with: A troglitazone $(100 \mu \mathrm{mol} / \mathrm{l})$, B tBHQ $(100 \mu \mathrm{mol} / \mathrm{l})$ or $\mathbf{C}$ xanthine (X: $150 \mu \mathrm{mol} / \mathrm{l})$-xanthine oxidase (XO: $15 \mathrm{mU} / \mathrm{ml}$ ) at different times. $n=4$ per data point. * Indicates $p<0.05$, compared to control group

with troglitazone $(100 \mu$ moles/l) at time intervals from $30 \mathrm{~min}$ to $24 \mathrm{~h}$ (data not shown). To investigate whether the troglitazone-inhibited activity of glyoxalase I was secondary to the increase in the cellular oxidative stress, the time-dependent effects of tBHQ or xanthine-xanthine oxidase on the activity of glyoxalase I as well as on the cellular oxidative stress levels were examined. There were no significant changes in the activity of glyoxalase I after the cells were treated with tBHQ $(100 \mu$ moles/l) at different time intervals (Fig 7B). A time-dependent biphasic change in oxidative stress was observed after the cells were treated with tBHQ (Fig. 7B). Within $1 \mathrm{~h}$ of treatment, the oxidative stress was increased. A prolonged incubation beyond $6 \mathrm{~h}$, however, resulted in a reduction in oxidative stress. The time-dependent activation of phase 2 enzymes, leading to the generation of GSH, might be responsible for this biphasic effect of $\mathrm{tBHQ}$. In an- 

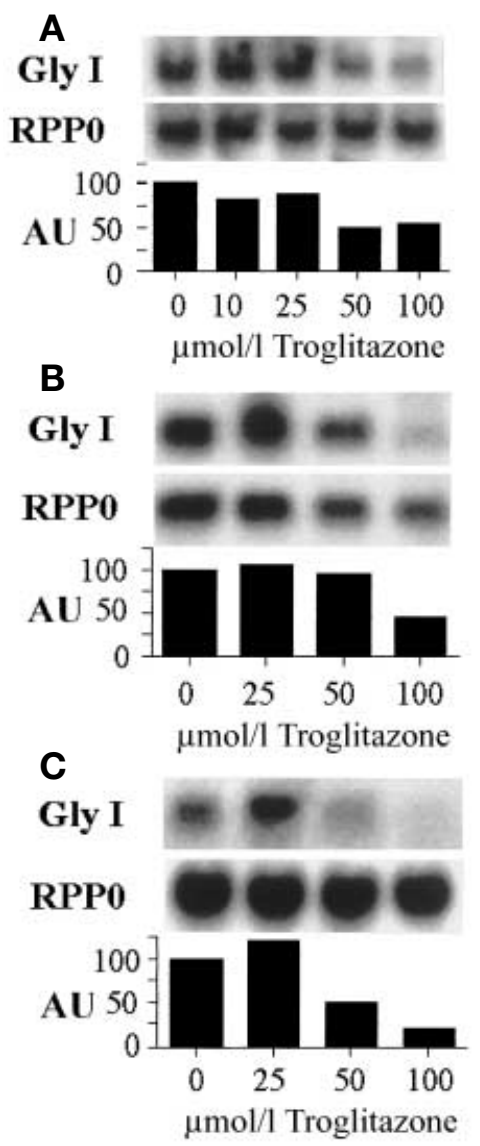

Fig. 8. Effect of an $8 \mathrm{~h}$ exposure to troglitazone on glyoxalase I (Gly 1) mRNA in human H11 astroglioma cells (A), rat cardiac myocytes $(\mathbf{B})$ and rat primary hepatocytes $(\mathbf{C})$. In the same Northern blots the RPP0 mRNA content was also determined and Gly I mRNA relative to RPP0 mRNA is plotted in arbitrary density units at the bottom of each figure

other group of experiments, xanthine $(150 \mu \mathrm{mol} / \mathrm{l})$ xanthine oxidase $(15 \mathrm{mU} / \mathrm{ml})$ generated a significant oxidative stress during the $24 \mathrm{~h}$ treatment but had no effect on the activity of glyoxalase I (Fig 7C).

In contrast to what was found in the H11 cells, troglitazone did not increase oxidative stress in rat hepatocytes.

The effect of troglitazone and rosiglitazone on glyoxalase I $m R N A$ levels. To examine whether reduced glyoxalase I enzyme activity was correlated with decreased mRNA contents, troglitazone was added to cultures of $\mathrm{H} 11$ cells and RNA isolated after $8 \mathrm{~h}$. Glyoxalase I mRNA contents were reduced relative to RPPO mRNA with $100 \mu \mathrm{mol} / \mathrm{l}$ troglitazone causing a $40 \%$ decrease in mRNA (Fig. 8 ) in H11 cells. When this was repeated in another set of experiments with troglitazone exposure time increased to $24 \mathrm{~h}$, glyoxalase I mRNA decreased by $65 \%$ (data not shown). These reductions in mRNA correlate well with those in glyoxalase I enzyme activity. To determine whether this troglitazone-induced reduction in glyoxalase I

\section{Gly I \\ RPPO}
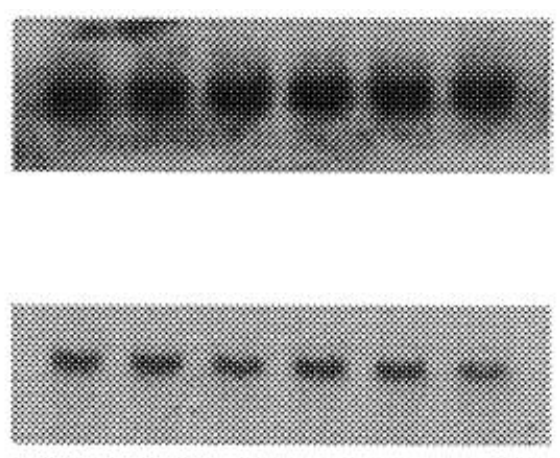

\section{$\begin{array}{lllll}0 & 5 & 10 & 25 & 50150\end{array}$ \\ Rosiglitazone $(\mu \mathrm{mol} / \mathrm{l})$}

Fig. 9. Effect of an 8 h exposure to rosiglitazone on glyoxalase I (Gly 1) mRNA in rat primary hepatocytes. In the same Northern blots the RPP0 mRNA content was also determined

mRNA is also present in other cell types, the effect of an $8 \mathrm{~h}$ exposure to troglitazone on glyoxalase I mRNA was examined in rat cardiac myocytes and hepatocytes. In these cell types, troglitazone caused a marked ( $85 \%$ and $65 \%$ respectively) reduction in glyoxalase I mRNA (Fig. 8).

To determine whether a decrease in glyoxalase I expression was a general property of all members of the thiazolidinedione family, the effect of rosiglitazone on glyoxalase I expression was examined in primary hepatocytes. Rosiglitazone had no effect on glyoxalase I expression (Fig. 9).

\section{Discussion}

Our data show that troglitazone down-regulates glyoxalase I mRNA content in at least three cell types: human astroglioma cells, rat cardiac myocytes and rat hepatocytes. The reduced glyoxalase I mRNA content correlated with a reduction in glyoxalase I enzyme activities in the cells examined, the human astroglioma cells and rat hepatocytes. In addition, lower glyoxalase I expression was associated with lower glyoxalase II activity. The inhibitory effect of troglitazone on the activity of glyoxalase I was concentration-dependent and time-dependent. This down-regulation does not seem to be a non-specific effect because troglitazone had no effect on the GSH contents, glutathione Stransferase activity or thioredoxin reductase activity. Furthermore, tBHQ increased GSH, glutathione Stransferase and thioredoxin reductase but had no effect on glyoxalase I and II activities.

Methylglyoxal and other $\alpha$-oxo-aldehydes give rise to AGEs [3]. Prolonged inhibition of the glyoxalase system might be expected to result in problems of increased advanced AGE production. Our study found 
that the decrease in glyoxalase I and II activities did correlate with increased AGE formation. Such AGEs can interact with either receptors for advanced glycation endproducts or with scavenger receptors [37]. Activation of such receptors can activate the respiratory burst, thereby increasing oxidative stress.

An inhibition of the glyoxalase system could help explain troglitazone-induced hepatotoxicity [38-40], particularly our observation that troglitazone increased oxidative stress in H11 human astroglioma cells, but not in rat hepatocytes. Our studies show troglitazone or a metabolite is a pro-oxidative agent in human astroglioma cells. One reason why troglitazone could be a pro-oxidant intracellularly is that in human beings, troglitazone is oxidized to a quinonelike compound by a number of cytochrome P450s (CYPs) including CYP1A1, CYP2C8, CYP2C19 and CYP3A4 [41]. Quinones can undergo redox cycling resulting in the formation of superoxide anion [42], thereby increasing oxidative stress. Troglitazone is not only metabolized by CYP3A4 but it also induces CYP3A4 in both human and rat hepatocytes [43]. Quinone redox cycling could account for the prolonged rise in oxidative stress in the human cells that we saw in our experiments. That no oxidative stress was observed in rat hepatocytes following exposure to troglitazone could be due to differences in metabolism of troglitazone between rat and human cells.

As indicated by previous experiments [44], the suppression of glyoxalase system where there is also an increase in the oxidative stress experienced by the cell could be deleterious for the cell, tissue and organ. The suppression of the glyoxalase system together with the reduced efficiency with which troglitazone is metabolized into a quinone, induces CYP3A4 or down-regulates the glyoxalase system or both and could be what determines which patients develop troglitazone-induced hepatotoxicity, a hepatoxicity with similarities to acetaminophen toxicity. Because there is allelic variation in both the CYP3A4 gene [45] and in the glyoxalase I gene [46, 47] there could well be differences amongst individuals in how readily troglitazone induces oxidative stress and how readily troglitazone down-regulates the glyoxalase system, thus possibly explaining why approximately $2 \%$ of patients receiving troglitazone [40] develop liver problems.

It is not known whether the troglitazone-induced reduction in glyoxalase $I$ is due to reduced mRNA stability or to reduced mRNA synthesis, although the latter is the more common mode of regulation. Troglitazone is a ligand for PPAR $\gamma$ [48] and many of the antihyperglycaemic and insulin-sparing effects of troglitazone appear due to the activation of this nuclear receptor [15]. One example of gene expression suppression by troglitazone is the inhibition of phosphoenolpyruvate carboxykinase gene expression [13]. Here, inhibition of phosphoenolpyruvate car- boxykinase by troglitazone is likely to occur through the activation of PPAR $\gamma$ because there are several PPAR consensus sequences in the promoter region of the gene [49]. Even if troglitazone reduces the transcription of glyoxalase I, it is not clear how it does so because there is no PPAR consensus sequence in the promoter region of glyoxalase I [50]. The thiazolidinedione BRL49653 also activates the $\operatorname{PPAR} \gamma$ receptor to down-regulate $o b$ gene expression; however, there are no PPAR consensus sequences in the $o b$ promoter region [51]. Rather activated PPAR $\gamma$ down-regulates $o b$ gene expression by inhibiting $\mathrm{C} / \mathrm{EBP}$-induced activation of the promoter [52]. Interestingly, there is also a C/EBP consensus site in the promoter region of glyoxalase I [50], and it could well be that a similar mechanism is at work in troglitazone's suppression of glyoxalase I gene expression. Also of interest is that there is a $\mathrm{C} / \mathrm{EBP}$ consensus site in the promoter region of the PPAR $\gamma$ gene [53], a gene whose promoter has no PPAR consensus sites but that is up-regulated by troglitazone [54].

In conclusion, troglitazone caused a specific decrease in glyoxalase I and II activities and a reduction in glyoxalase I mRNA activities. Rosiglitazone, on the other hand, had no effect on glyoxalase I gene expression. Rosiglitazone is a thiozolidinedione with no known hepatotoxic activity [55]. The inhibition of the glyoxalase system and the concurrently increased oxidative stress could possibly account for the hepatotoxicity occasionally observed following prolonged treatment with troglitazone.

Acknowledgements. L. Wu was supported by a fellowship award from the Canadian Institutes for Health Research/ Heart and Stroke Foundation of Canada of Saskatchewan. E. Eftekharpour was supported by a scholarship from the Ministry of Education, Government of Iran. This work was supported by Medical Research Council of Canada grant MT 13467 (to BHJJ) and the Canadian Diabetes Association (WJR). The authors are also grateful to Mrs. C. Wong for her excellent technical assistance.

\section{References}

1. McLellan AC, Thornalley PJ, Benn J, Sonksen PH (1994) Glyoxalase system in clinical diabetes mellitus and correlation with diabetic complications. Clin Sci (Colch) 87: 21-29

2. Thornalley PJ (1990) The glyoxylase system: new developments towards functional characterization of a metabolic pathway fundamental to biological life. Biochem J 269: $1-11$

3. Thornalley PJ (1996) Pharmacology of methylglyoxal: formation, modification of proteins and nucleic acids, and enzymatic detoxification - a role in pathogenesis and antiproliferative chemotherapy. Gen Pharmacol 27: 565-573

4. Atkins TW, Thornalley PJ (1989) Erythrocyte glyoxalase activity in genetically obese (ob/ob) and streptozotocin diabetic mice. Diabetes Res 11: 125-129 
5. Phillips SA, Mirrlees D, Thornalley PJ (1993) Modification of the glyoxalase system in streptozotocin-induced diabetic rats. Effect of the aldose reductase inhibitor Statil. Biochem Pharmacol 46: 805-811

6. Ranganathan S, Walsh ES, Tew KD (1995) Glyoxalase I in detoxification: studies using a glyoxalase I transfectant cell line. Biochem J 309: 127-131

7. Beisswenger PJ, Howell SK, Touchette AD, Lal S, Szwergold BS (1999) Metformin reduces systemic methylglyoxal levels in type 2 diabetes. Diabetes 48: 198-202

8. Nolan JJ, Ludvik B, Beerdsen P, Joyce M, Olefsky J (1994) Improvement in glucose tolerance and insulin resistance in obese subjects treated with troglitazone. N Engl J Med 331: 1188-1193

9. Cavaghan MK, Ehrmann DA, Byrne MM, Polonsky KS (1997) Treatment with the oral antidiabetic agent troglitazone improves beta cell responses to glucose in subjects with impaired glucose tolerance. J Clin Invest 100: 530-537

10. Fujiwara T, Yoshioka S, Yoshioka T, Ushiyama I, Horikoshi H (1988) Characterization of new oral antidiabetic agent CS-045. Studies in KK and ob/ob mice and Zucker fatty rats. Diabetes 37: 1549-1558

11. Yoshioka S, Nishino H, Shiraki T et al. (1993) Antihypertensive effects of CS-045 treatment in obese Zucker rats. Metabolism 42: 75-80

12. Asano M, Nakajima T et al. (1999) Troglitazone and pioglitazone attenuate agonist-dependent $\mathrm{Ca} 2+$ mobilization and cell proliferation in vascular smooth muscle cells. Br J Pharmacol 128: 673-683

13. Davies GF, Khandelwal RL, Roesler WJ (1999) Troglitazone inhibits expression of the phosphoenolpyruvate carboxykinase gene by an insulin-independent mechanism. Biochim Biophys Acta 1451: 122-131

14. Ribon V, Johnson JH, Camp HS, Saltiel AR (1998) Thiazolidinediones and insulin resistance: peroxisome proliferatoractivated receptor gamma activation stimulates expression of the CAP gene. Proc Natl Acad Sci U S A 95: 14751-14756

15. Saltiel AR, Olefsky JM (1996) Thiazolidinediones in the treatment of insulin resistance and type II diabetes. Diabetes 45: 1661-1669

16. Inoue I, Katayama S, Takahashi K et al. (1997) Troglitazone has a scavenging effect on reactive oxygen species. Biochem Biophys Res Commun 235: 113-116

17. Shinohara M, Thornalley PJ, Giardino I et al. (1998) Overexpression of glyoxalase-I in bovine endothelial cells inhibits intracellular advanced glycation endproduct formation and prevents hyperglycemia-induced increases in macromolecular endocytosis. J Clin Invest 101: 1142-1147

18. Prestera T, Zhang Y, Spencer SR, Wilczak CA, Talalay P (1993) The electrophile counterattack response: protection against neoplasia and toxicity. Adv Enzyme Regul 33: 281-296

19. Meister A (1983) Glutathione. Ann Rev Biochem 79: 711-760

20. Galloway DC, Blake DG, Shepherd AG, McLellan LI (1997) Regulation of human gamma-glutamylcysteine synthetase: co-ordinate induction of the catalytic and regulatory subunits in HepG2 cells. Biochem J 328:99-104

21. Christman JW, Blackwell TS, Juurlink BHJ (2000) Redox regulation of nuclear factor kappa B: therapeutic potential for attenuating inflammatory responses. Brain Pathol 10: 153-162

22. Juurlink BHJ, Walz W (1998) Neural cell culture techniques. In: Boulton, AA, Baker GB, Bateson AN (eds), vol 33. Humana Press, Totowa, pp 53-104
23. Kimes BW, Brandt BL (1976) Properties of a clonal muscle cell line from rat heart. Exp Cell Res 98: 367-381

24. Cascales C, Mangiapane EH, Brindley DN (1984) Oleic acid promotes the activation and translocation of phosphatidate phosphohydrolase from the cytosol to particulate fractions of isolated rat hepatocytes. Biochem J 219: 911-916

25. McLellan AC, Thornalley PJ (1989) Glyoxalase activity in human red blood cells fractioned by age. Mech Ageing Dev 48: 63-71

26. Habig WH, Jakoby WB (1981) Assays for differentiation of glutathione S-transferases. Methods Enzymol 77: 398-405

27. Holmgren A, Björnstedt M (1995) Thioredoxin and thioredoxin reductase. Methods Enzymol 252: 199-208

28. Eftekharpour E, Holmgren A, Juurlink BHJ (2000) Thioredoxin reductase and glutathione synthesis is upregulated by $t$-butylhydroquinone in cortical astrocytes but not in cortical neurons. Glia 31: 241-248

29. Smith PK, Krohn RI, Hermanson GT et al.C (1985) Measurement of protein using bicinchoninic acid. Anal Biochem 150: 76-85

30. Juurlink BHJ, Schültke E, Hertz L (1996) Glutathione release and catabolism during energy substrate restriction in astrocytes. Brain Res 710: 229-233

31. Thorburne SK, Juurlink BHJ (1996) Low glutathione and high iron govern the susceptibility of oligodendroglial precursors to oxidative stress. J Neurochem 67: 1014-1022

32. Monnier VM, Kohn RR, Cerami A (1984) Accelerated age-related browning of human collagen in diabetes mellitus. Proc Natl Acad Sci U S A 81: 583-587

33. Lee KW, Simpson G, Ortwerth B (1999) A systematic approach to evaluate the modification of lens proteins by glycation-induced crosslinking. Biochim Biophys Acta 1453: 141-151

34. Ranganathan S, Walsh ES, Godwin AK, Tew KD (1993) Cloning and characterization of human colon glyoxalase-I. J Biol Chem 268: 5661-5667

35. Laborda J (1991) 36B4 cDNA used as an estradiol-independent mRNA control is the cDNA for human acidic ribosomal phosphoprotein PO. Nucleic Acids Res 19: 3998

36. Björnstedt M, Kumar S, Bjorkhem L, Spyrou G, Holmgren A (1997) Selenium and the thioredoxin and glutaredoxin systems. Biomed Environ Sci 10: 271-279

37. Thornalley PJ (1998) Cell activation by glycated proteins. AGE receptors, receptor recognition factors and functional classification of AGEs. Cell Mol Biol 44: 1013-1023

38. Kohlroser J, Mathai J, Reichheld J, Banner BF, Bonkovsky HL (2000) Hepatotoxicity due to troglitazone: report of two cases and review of adverse events reported to the United States Food and Drug Administration. Am J Gastroenterol 95: 272-276

39. Malik AH, Prasad P, Saboorian MH, Thiele DL, Malet PF (2000) Hepatic injury due to troglitazone. Dig Dis Sci 45: 210-214

40. Murphy EJ, Davern TJ, Shakil AO et al. (2000) Troglitazone-induced fulminant hepatic failure. Acute Liver Failure Study Group. Dig Dis Sci 45: 549-553

41. Yamazaki H, Shibata A, Suzuki M et al. (1999) Oxidation of troglitazone to a quinone-type metabolite catalyzed by cytochrome P-450 2C8 and P-450 3A4 in human liver microsomes. Drug Metab Dispos 27: 1260-1266

42. Comporti M (1989) Three models of free radical-induced cell injury. Chem-Biol Interact 72: 1-56

43. Sahi J, Hamilton G, Sinz M et al. (2000) Effect of troglitazone on cytochrome P450 enzymes in primary cultures of human and rat hepatocytes. Xenobiotica 30: 273-284 
44. Ankrah NA, Ekuban FA, Asamoah EB (1990) Depressant effect of very low levels of aflatoxin B1 on mouse glyoxylase-I activity and methylglyoxal disposal. Biochem Pharmacol 39: 1261-1263

45. Sata F, Sapone A, Elizondo G et al. (2000) CYP3A4 allelic variants with amino acid substitutions in exons 7 and 12: evidence for an allelic variant with altered catalytic activity. Clin Pharmacol Ther 67: 48-56

46. Arnaud J, Constans J, Sevin J, Sorbara M (1988) Population polymorphism of the GLO1 enzyme. Identification of two new variants. Gene Geogr 2: 57-64

47. Thornalley PJ (1991) Population genetics of human glyoxalases. Heredity 67: 139-142

48. Forman BM, Tontonoz P, Chen J, Brun RP, Spiegelman BM, Evans RM (1995) 15-Deoxy-delta 12, 14-prostaglandin J2 is a ligand for the adipocyte determination factor PPAR gamma. Cell 83: 803-812

49. Tontonoz P, Hu E, Devine J, Beale EG, Spiegelman BM (1995) PPAR gamma 2 regulates adipose expression of the phosphoenolpyruvate carboxykinase gene. Mol Cell Biol 15: $351-357$
50. Ranganathan S, Ciaccio PJ, Walsh ES, Tew KD (1999) Genomic sequence of human glyoxalase-I: analysis of promoter activity and its regulation. Gene 240: 149-155

51. De Vos P, Lefebvre AM, Miller SG et al. (1996) Thiazolidinediones repress ob gene expression in rodents via activation of peroxisome proliferator-activated receptor gamma. J Clin Invest 98: 1004-1009

52. Hollenberg AN, Susulic VS, Madura JP et al. (1997) Functional antagonism between CCAAT/Enhancer binding protein-alpha and peroxisome proliferator-activated receptor-gamma on the leptin promoter. J Biol Chem 272: 5283-5290

53. Fajas L, Auboeuf D, Raspe E et al. (1997) The organization, promoter analysis, and expression of the human PPARgamma gene. J Biol Chem 272: 18779-18789

54. Davies GF, Khandelwal RL, Roesler WJ (1999) Troglitazone induces expression of PPAR $\gamma$ in liver. Mol Cell Biol Res Commun 2: 202-208

55. Balfour JA, Plosker GL (1999) Rosiglitazone. Drugs 57: 921-930 